\title{
Entering a risky territory: space in the age of digital navigation
}

\author{
Valérie November, Eduardo Camacho-Hübner \\ Ecole Polytechnique Fédérale (EPFL), ENAC INTER ESpRi, BP 2133 (Bâtiment BP), Station 16, \\ 1015 Lausanne, Switzerland; e-mail: valerie.november@epfl.ch
}

\section{Bruno Latour}

Sciences Po, 27 rue Saint-Guillaume, 75007 Paris, France; e-mail: bruno.latour@sciences-po.fr Received 14 August 2009; in revised form 29 December 2009

\begin{abstract}
Relying on the fecund interface of three fields - studies in science, risk geography, and knowledge management - this paper notes first that the lack of understanding of the relationships between maps and territory and risks is an unfortunate consequence of the way the mapping impulse has been interpreted during the modernist period. Then, taking into account the advent of digital navigation, the paper discusses a very different interpretation of the mapping enterprise that allows a mimetic use of maps to be distinguished from a navigational one. Consequently, we suggest maps should be considered as dashboards of a calculation interface that allows one to pinpoint successive signposts while moving through the world, the famous multiverse of William James. This distinction, we argue, might, on the one hand, help geography to grasp the very idea of risks and, on the other, help to free geography from its fascination with the base map by allowing a whole set of new features, such as anticipation, participation, reflexivity, and feedback, now being included in the navigational definition of maps.
\end{abstract}

\section{Introduction}

When social scientists collaborate with geographers, they are often puzzled by the weight given by their colleagues to the base map, ${ }^{(1)}$ upon which they are asked to project their own objects as if they had to add a more superficial layer to a more basic one. This is never more true than in the domain of risks. Geographers insist that their colleagues in sociology, economics, anthropology, and psychology place their interpretation of risks on top of the base map, which is supposed to ground the most fundamental, the most material, and, above all, the most physical reality. Such a collaboration has the great drawback of making it impossible to go beyond the distinction between 'objective' and 'subjective' risks. Risks are today a crucial question for our societies, and by their nature they bring different scientific disciplines together. Mapping risks has forced us to look closer at the ambiguous role of maps. Our paper tackles some of the reasons why this emphasis on the base map does not need to characterise the skills of geographers and offers an alternative way for social scientists and geographers to collaborate by circumventing a well-entrenched distinction between 'physical' and 'human' geography. To somewhat dramatize the issue, we claim that risks should be as easy to put on a map as reefs. There is no reason why reefs, which might threaten the navigation of ships and yachts, should be easier to map by pinpointing their exact location using their longitude and latitude and symbollically indicating their presence and it be so difficult for the same cartographers to map risks (fire, flood, pollution, unemployment, crime, etc) that a given population might have to take into account. ${ }^{(2)}$ There is no reason to think that reefs pertain more 'naturally' to the base

(1) The base map refers here to its French equivalent fond de carte. This kind of map is currently used as a basic layer upon which other sets of information may be represented. It is also known as 'mother map' or 'outline map'.

(2) For a good demonstration of this see Monmonier (1997). 
map and are any closer to the fundamental layer and that risks should be added like more superficial layers on top of the first. We want to reconsider the mapping impulse so that reefs and risks belong equally to the definition of 'territory'-both being obstacles to courses of action that should be registered and marked through sets of conventions on many kinds of maps.

This puzzle has led us to question the relationships among maps, territory, and risks. Is a map, as Pickles (2004) points out, not a representation of the world but an inscription that does (or sometimes does not) work in the world? Do maps and mapping precede the territory they 'represent', or can they be understood as producing it? Many authors have already proposed to deeply revise commonsense ideas on the emergence of territory (Elden, 2005; Glennie and Thrift, 2009; Paasi, 2003; Painter 2009). ${ }^{(3)}$ And just as many authors have revised the traditional role given to maps. Here, too, different schools of thoughts are present, from those who focus on depicting the political and institutional relations of mapping (Akerman, 2009; Harley, 1989; Pickles, 2004) to those more focused on the performative use of maps (Cosgrove, 1999) and an understanding of maps as emerging through a diverse set of practices (Crampton, 2009; Dodge et al, 2009). On the risk side, the same revision prevails, from a probabilistic understanding of the phenomenon to a relational conception of it [as proposed by Healy (2004) and November (2004; 2008), for instance]. Although all of those revisions have been very inspirational, the three notions of maps, territory, and risk have not yet been brought together as one single puzzle.

We want to show here, thanks to the fecund interface of three fields-studies in science, risk geography, ${ }^{(4)}$ and knowledge management - that the lack of understanding of this relationship between maps and territory and risks is an unfortunate consequence of the way the mapping impulse has been interpreted during the modernist period - from the 18th to the end of the 20th century (Latour, 1993). We want to argue that, because of the advent of digital navigation (Cartwright and Hunter, 1999; Fabrikant, 2000), a very different interpretation of the mapping enterprise can be introduced that allows a mimetic use of maps to be distinguished from a navigational one. This distinction, in turn, might help geography to grasp the very idea of risks and go beyond its divide between 'objective' and 'subjective' as well as 'physical' and 'human' as some geographers have already exhorted us to do (Harrisson et al, 2004; Lane, 2001; Massey, 2000; Thrift, 2002).

\section{Maps have always been platforms of calculation interface}

Even though maps were already ubiquitous in print form, it is now clear to all their users that they have undergone a major shift thanks to the availability of digital technologies (Crampton, 2003; Dodge et al, 2009). Not only has their ubiquity increased exponentially-GPS are now in all cars, in every hand-held computer, and in so many mobile phones-but they now appear much more often in a digital format

(3) We are aware that the meaning of this notion varies also between the Francophone and the Anglo-American community of geographers [see Fall (2007) on the difficulties of concept traveling, Debarbieux (1999) for an exercise in comparison]. In this paper we refer to Lévy (1994), Lévy and Lussault (2003), Lussault (2007), and Raffestin (1986; 1997) and their theoretical definitions of space and territory. Also see Painter (2009, page 64), who says territories can be understood as "configurations of mobile objects-in-relation".

(4) Thanks to the seminal work of such geographers as Bingham and Thrift (2000), Hetherington (1997), Hinchliffe (1996), Murdoch (1997; 1998), Thrift (1996), Whatmore (2001), and of such sociologists of science as Callon and Law (2004), and Latour (1993; 1997; 2005). Law (2002; 2004) Law and Mol (2001), to name a few, we can take for granted that geography and sociology of science have many concepts in common-many of these papers having been published in special issues in this journal. 
than they do on paper. When they still appear on paper, as is the case when one prepares a trip or sends instructions to friends, chance is that this piece of paper is only a printout from a tiny fraction of a computerized databank, a frozen image that will be thrown away after it has been used. While in precomputer times ('BC', as geeks say) a map was a certain amount of folded paper you could look at from above or pinned down on some wall, today the experience we have of engaging with mapping is to log into some databank, which gathers information in real time through some interface (usually a computer). Printing has become optional. The paper map, which was so central to the mapping experience, is now just one of the many outputs that the digital banks may provide, something we can switch on or off for convenience-just as we do with our printer-but that no longer defines the whole enterprise.

At first sight, a navigational interface like Google Earth may feel like a good old survey of a satellite photograph or paper map, except it is much easier to 'fly over'. But this impression of familiarity soon becomes disturbingly odd when you can switch with one click from cartography to photography, from $2 \mathrm{D}$ to $3 \mathrm{D}$, from small scale to large scale, depending on the choice you make of various overlays. And this ease of navigation is nothing compared with the shock one may feel when suddenly totally bizarre types of information pop up at you: advertisement for some Pizza Hut joint, street views taken by complete strangers, moving images transforming part of the scene into real-time videos, projections on the screen of historical information, alerts to the presence in the neighborhood of some people you may have befriended through some freshly designed social networks. To be sure, all those pieces of information could have been made available on BC maps, but each would have had to be printed on a separate broadsheet or added on a separate medium. Now, because of the digital compatibility of all those heterogeneous forms of media, they can be entered in similar types of databanks and be made available according to your queries and recalculated every time in real time. An added bonus is that the platform allows the user to add fresh personal information to the bank, thus transforming the user of the map into one of its myriad amateur contributors.

To be sure, this is not a new experience for practicing geographers used to the notion of interactive cartography since the 1980s and to Google Earth since 2005 (see Crampton, 2003; Goodchild, 2007), but it is for sure a new experience for the masses now engaged in using maps very differently. How does one define what is original in this collective experiment? Let's say that when we log in through some interface into some geographical databank, our computer screen (fixed or portable, this no longer matters) plays the role of a dashboard allowing us to navigate through totally heterogeneous sets of data, which are refreshed in real time and localized according to our specific queries (Cartwright, 1999; Pointet, 2007). So, even though the experience of digital navigation may at first sound like a mere extension of the older experience of looking at geographical data and combining it with some other types of information, after a while the number of new traits is so large that one is forced to confess that this is indeed a new experience (Bowker, 2006). Our analysis is that digital technologies have reconfigured the mapping experience into something else that we wish to call a navigational platform that is characterized by the presence of:

- Databanks.

- Some interface for data handling, ie, calculation, treatment, and retrieval.

- A dashboard for interfacing with the users both ways.

- Many different outputs tailored to a great variety of users - one of the outputs being paper printouts. 
What we mean today by 'looking at a map' is 'logging onto some navigational platform' and may be, but no longer necessarily, printing some chunk of it to help circumnavigate through some complicated trajectory.

If we emphasize the novelty of the experience offered to everyone of us by the advent of digital mapping, it is not to indulge any sort of technical hype. On the contrary, it is to seize the occasion to realize how much the older BC mapping was already providing its users with all the benefits of a navigational platform. When we now look in retrospect to the many various ways in which maps were really experienced by their practitioners, we see that they have always been used as a rather complex and variegated interface of calculation for navigational purposes.

So, we can now reinterpret the mapping impulse by recognizing six essential features that have always been there-BC (before computers) as well as AC (after computers):

- Acquisition of data: this is the work of first surveying a land by navigating through it (heroically at first and routinely now).

- Management of data: this refers to the institutions that are necessary to gather, house, conserve, archive, maintain, and standardize masses of acquired data.

- Recalculation of data: the cumulative effects that centers of calculation allow by the superposition and cross reference of many types of heterogeneous information made more or less coherent through conventions and standards and recalculated thanks to many successive inventions in mathematics and data handling.

- Printout: the provisional outputs of the platform as they are produced for various types of customers and usages.

- Signposts: the many artifacts that are aligned so as to render the printout usable and to establish some correspondence (more of this below) between two successive pieces of information.

- Navigational usage: the variegated ways in which the platform is being put to use by many different types of endusers.

Although huge differences exist between the early work of courageous explorers and cartographers (Alder, 2003; Trystram, 2001), and the use of GPS and remote sensing, we wish to claim that those six features have always been present and that, if digital techniques have vastly accelerated the moves and provided many new accelerated feedback loops between those steps, their net result is to have made more salient the presence of this long chain of production that existed already in the past (Carpo, 2001). In other words, if you could easily forget the masses of institutions, skills, conventions, and instruments that went into the making of a beautifully printed atlas, it is much more difficult to do so now that we are constantly reminded of the number of satellites presiding over our GPS, of the sudden disappearance of network coverage, of the variations in data quality, of the irruption of censorship, of the inputs of final users in sending data back, and so on. As usual, far from increasing the feeling of dematerialization, digital techniques have rematerialized the whole chain of production. Today it is impossible to ignore that, whenever a printed map is available, there exist, upstream as well as downstream, a long and costly chain of production that requires people, skills, energy, software, and institutions and on which the constantly changing quality of the data always depends. If BC every geographer knew that (after all, it was part and parcel of their daily practice), in the AC era every enduser is prone to feel the presence of those networks as well. 


\section{Navigational versus mimetic interpretation of maps}

It is this new salience of the whole chain of production that we want now to use in order to highlight a puzzling feature of maps: if maps have always been part of this chain, why have they been interpreted as having a correspondence with a physical territory? Is it possible that the very notion of territory is tied to a certain fascination with maps - a fascination due to the overlooking of the whole chain of production? That the map is not the territory every reader of Borges's rather too famous fable "Of exactitude in science" knows very well (Borges, 2004). But we have another reason to think that such a project could produce only 'unconscionable maps': what is called the 'land' to be overlaid by a scale one cartography might not exist either; it might be an artifact, a belated consequence of a wrong philosophy applied to the cartographic enterprise. With the digital ubiquity of mapping, we are literally entering a 'new territory' that is so new it bears almost no resemblance with what was called 'territory' before. (5)

To understand this, one has only to get closer to the ways the correspondence between maps and lands is made in practice (Hutchins, 1995; Kitchin and Dodge, 2007).(6) Consider a simple example: all yachtsmen know that the navigator inside the cabin is busy using the map laid out in front of her to calculate with ruler and compass the best route taking into account the many shreds of information shouted at her from the cockpit. For the navigator, the map is indeed like a $2 \mathrm{D}$ slide-rule that incorporates in a precalculated format huge masses of information about angles and distances and on which is overlaid in various fonts other types of informationtoponyms, average strength of currents, range of tides, seamarks and landmarks, shapes of reefs and wrecks, various regulations, and so on. The only difference between the situation $\mathrm{BC}$ and $\mathrm{AC}$ is the navigator had to do everything on the very surface of the beautiful and water-proof shining paper map and not, as she would do nowadays by logging onto her GPS-equipped laptop, on a screen through a keyboard. It requires no great leap of imagination to redescribe the navigator's workplace as a platform interface of calculation in both situations - with this difference that there is paper in one and may be no paper in the other.

Now the navigator tries to establish some relation between some of the features on the map and the warnings shouted at her from the cockpit by her team members whose views are made fuzzy by the sea spray, their voices covered by the roar of the waves, and their hearts excited by the heat of the race. Even if she had learned her Descartes by heart, she would never fancy for one minute that the skipper and the crew live in some 'outside world' that would resemble the geometric one she is looking at; too many features would not obviously fit in this geometrical world: the spray, the waves, the heat, the excitation of the treacherous landscape, the skills of the maneuvers. But it would be just as wrong to believe that the navigator, because she is down in the cabin looking over the map tracing their tacks on paper with ruler and compass, resides 'in' a geometrical space (Ingold, 2007). The relation she is looking for is based not on some resemblance between the map and the territory but on the detection of relevant cues allowing her team to go through a heterogeneous set of datapoints from one signpost to the next: some signposts are made visible from the cockpit in the hurly burly world (for instance, a roaring red buoy that the crew was desperately trying to tack), and some are visible in the no less hurly burly nauseating world of the cabin (for instance, a dark spot on the map with a red tip, which is just at the right angle expected by the

(5) See, for instance, literature on globalization, where a similar thinking also emerges (Amin, 2002; Elden, 2005; Sheppard, 2002).

(6) Vertesi (2008) describes this correspondence in the case of the London Underground map and its users. 
navigator since the last beacon has been safely recognized and pinpointed with a blue pencil).

What is clear from the example of the continually renegotiated connection between the navigator and the skipper in the cockpit is that in the past we might have confused two entirely different meanings of the word 'correspondence': the first seems to rely on a resemblance between two elements (signs on the map and territory, or more philosophically words and worlds), while the second emphasizes the establishment of some relevance that allows a navigator to align several successive signposts along a trajectory. While the first meaning implies what James called a salto mortale (deadly jump) between two, and only two, endpoints through a huge gap, the second defines what James called a deambulation between many successive stepping stones in order to achieve the miracle of reference by making sure that there is as little a gap as possible between two successive links (James, 1996a). Both are depending on correspondence, but one engages the mapping impulse into an impasse (ironically recorded by Borges's fable: is the map similar to the territory?) while the other allows one to move away from it and deploy the whole chain of production that has always been associated with map making - as we recognized above. To clarify the difference between the two meanings, we are going to call the first one the mimetic interpretation and the second the navigational interpretation of maps.

Why navigational? Because we argue that the common experience of using digital maps on the screen, and no longer on paper, has vastly extended the meaning of the word navigation. In effect, we are led back to the earliest use of the map-making impulse (Jacob, 1992), not only in the maritime sense of the word but in the vastly enlarged meaning that is now familiar through digital worlds (Cartwright, 1999). The users of the platforms are engaged in receiving and sending information to allow other agents to find their way through a maze of data: it could be data about the yacht's trajectory (as in the example of the navigator above), in a digital library (Bowker, 2006; Fabrikant and Buttenfield, 2001), or through a social network or through a city. It does not matter: everyone now has the experience of navigating through successive signposts on screen. The $\mathrm{BC}$ and $\mathrm{AC}$ meaning of navigation taken literally or figuratively are thus in continuity with one another. The whole history of cartography would show, if it is taken as a practical activity, all the explorers, navigators, cartographers, geometers, mathematicians, physicists, military personnel, urban planners, and tourists that have 'logged in', so to speak, on those 'platforms' in order to feed the 'databanks' with some piece of information, or to draw the maps, or to use them in some way to solve their navigational problems (Chrisman, 1997; Collectif, 1980). ${ }^{(7)}$

In all those cases, there is indeed a correspondence, but it works precisely because it is not mimetic. What counts in the example of the yacht is that the data sunk into the sea by the Nautical Service under the form of a roaring buoy bear some relation (angles especially) with the map that uses the same standards to code the same data (longitude and latitude) to which have been added several international conventions on how to design and where to sink the buoys and how to decide how to print signs on the maps. To be sure, there are plenty of mathematics, plenty of geometry, plenty of realities, plenty of correspondences, plenty of signposts in the world interpreted in its navigational dimension, but they are not distributed in the same way as with the mimetic dimension: they do not divide in two, so as to form a real analogical 'outside' and a mapping representational one 'inside'.

(7) It is on those principles that the mapping of scientific and technical controversies of the MACOSPOL project (http://www.macospol.eu/) as well as the demoscience consortium of teaching those 'cartographic' techniques (http://www.demoscience.org/) are developed. 
Let us already note that in such a redescription reefs and risks, reefs as risks, are one and the same for the navigator: obstacles along the way she and her crew try to circumvent. We may now begin to sense why risk cartography is at once so difficult and so rewarding: there would be no meaning in having a mimetic interpretation of risks as if there were 'out there' objective risks - for instance, disasters or catastrophes - which would then be mapped. It is clear that in the case of risks what should be recorded is rather a long collection of signposts (reefs, buoys, tidal information, algorithms, etc) and warnings (eg meteoalerts) that define complex paths through series of risk institutions and practices. And yet, this does not mean that one has to fall upon a merely subjective definition of risks. It is precisely because risks cannot be fully calculated that they may escape the fate of being divided into an objective reality to which one should then add a subjective interpretation. ${ }^{(8)}$ A sturdy and realistic mapping of the trajectories through risk paths is perfectly possible, but on the condition of bypassing the mimetic interpretation given of maps.

To sum up the argument so far, we can offer this diagram (figure 1) showing the same map interpreted in two orthogonal ways: the first one, the navigational one, inserts the map into a deambulation from one signpost to the next and establishes various correspondences within sets of heterogeneous media; the second interpretation, the mimetic one, imagines that there exist, because the navigational impulse has been forgotten, two sets of images that should resemble one another.

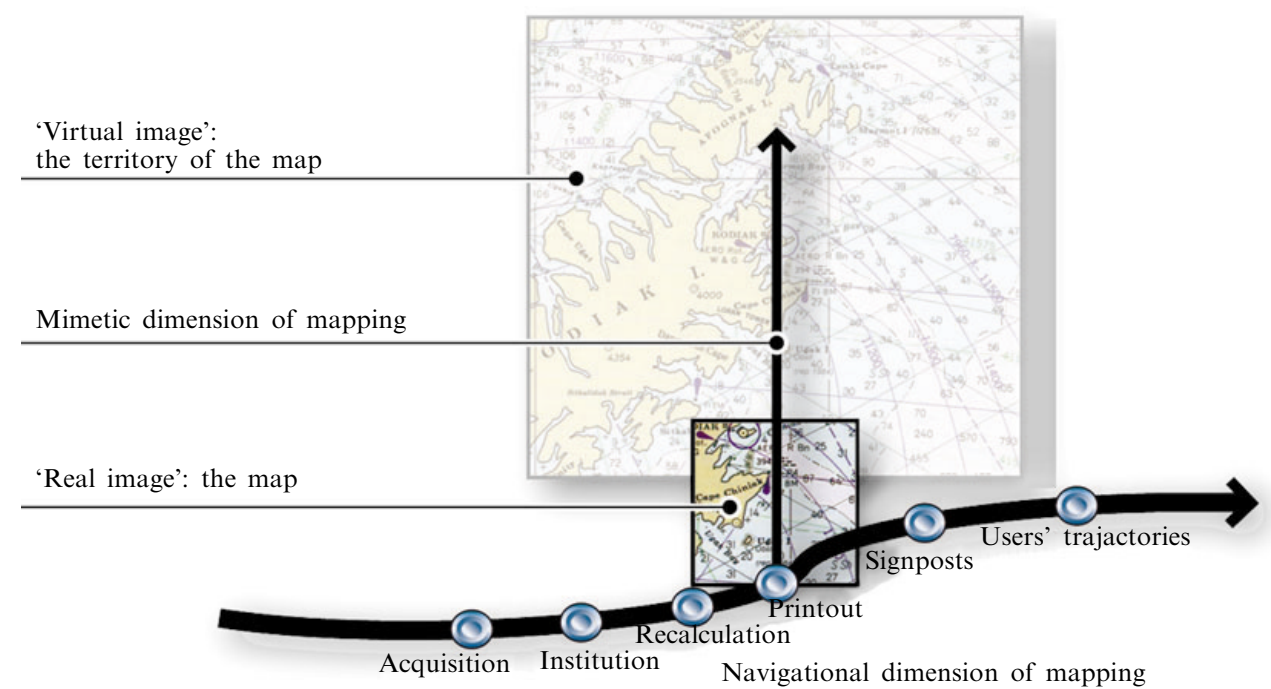

Figure 1 [In color online, see http://dx.doi.org/10.1068/d10409] Two orthogonal interpretations of the mapping impulse (source: base map comes from the National Oceanic and Atmospheric Administration; alterations are authors' own).

(8) This is what Beck has emphasized about the terrorist threat: "as soon as we speak in terms of 'risk', we are talking about calculating the incalculable, colonizing the future" (2002, page 40). Also see Thrift, who says: "I want to extend these thoughts in various directions, hoping to capture the outlines of a world just coming into existence, one which is based on continuous calculation at each and every point along each and every line of movement" (2004, page 583). Also, the calculative mode of thinking as part of the notion of territory is present in Elden (2005). 


\section{Learning to see territory as a 'spurious referent'}

What we are now going to argue is that these two sets of images are actually an optical illusion and that there exists in effect, only one, the print map-thus suggesting that it is difficult to detect in the notion of territory what is not coming from the map. But for this we should leave the case of maps and make a little detour through scientific inscriptions more generally.

One of the striking results of the study of scientific visualization has been to show that a given image loses its scientific meaning once taken out of the cascade of antecedent and posterior images inside which it is inserted (Latour, 1986; 1987; Lynch and Woolgar, 1990; Pinch, 1986). To summarize a large body of work: an isolated image has no scientific referent-but it generates, of course, like all images, a virtual image, the 'what' that it is said to be the representation 'of'. Taken in isolation, an electronic microscopic image of a virus, a photograph of a galaxy, and the drawing of a skeleton in a natural history museum have no specific value (even though they might have powerful aesthetic, pedagogical, or rhetorical strength). If you want to understand what an isolated inscription means in science, you have to reinsert it inside the cascade of other inscriptions out of which it has been extracted. A glance at scientific papers is enough to show that the proof never resides in one visual display but in the invisible constant that is conserved through the many intermediary steps leading from one inscription to the next (Netz, 2003) [and the series would be even longer if followed through the laboratory practices (see Latour, 1999)]. Any given image is always preceded or followed by long series of graphs, tables, equations, legends, and paragraphs, and it is the series in its entirety that can be said to 'have a referent' or to prove something incontrovertibly (Daston and Galison, 2007). In other words, writing or reading a scientific paper heavily resembles the laying out of signposts that we have just described as the only practical way through which maps are generated.

The important point for us here is that, contrary to what a common philosophy of science would lead us to believe, a scientific inscription is never engaged in a correspondence between two and only two endpoints: the representation and the model. There are indeed many correspondences between scientific inscriptions - and this is why the sciences are so often able to produce objective knowledge-but those correspondences are always between one inscription and its many antecedents and consequents along the series of inscriptions that are being generated by instruments, theories, and calculations. Paradoxically (at least for the common view), it is because the series is uninterrupted and never broken down to the point of jumping 'outside' that that objectivity may be reached by accessing phenomena that would be inaccessible without them.

As soon as you break the cascade, an isolated image loses its scientific or referential character and enters a totally different trajectory. It becomes 'mimetic' - that is, it generates as a sort of halo a spurious referent that may seem very convincing but that has, in effect, no practical counterpart: it is the mere redoubling of what is being shown in the image. It leads you nowhere except to the equally spurious question of its 'resemblance' with an original model - that is created by the representation itself. To decide whether a photograph of a galaxy is really objective or not, you have to reconnect the photograph with the long cascade of other inscriptions out of which it has been taken. And the crucial point here is that those inscriptions do not resemble the photograph - and it is precisely this lack of resemblance that allows a gain in certainty as to the objective quality of the photograph (Latour, 1999). From a scientific point of view, a mere replication or resemblance between one inscription and the next would be a loss of objective information. Correspondence between successive dissimilar inscriptions is not to be confused with a resemblance between one image and its model. 
To sum up, not only maps but all scientific inscriptions may be framed in two orthogonal ways: the mimetic one (in fact a resemblance between an image and its virtual image) and the navigational one (a connection between one set of signposts and those dissimilar posts that precede and follow them). There is no doubt that in terms of gaining information, only the second one may provide objective knowledge. The first one is nothing but a narcissistic contemplation of one's own image.

At this point in our argument, there is a well-known danger that could paralyze the reflection: that we are making here a critical point about either the lack of exactitude of mapping techniques or, even worse, about the 'nonexistence' of an outside world. We beg the readers not to indulge in this facile turn of mind and to notice instead that those two questions - 'is the map an accurate representation or not?' (Borges's question), and 'is there a real world outside of the map?' (the realist's question) - are both depending on understanding the map in a mimetic way, which is precisely the way out of which we try to escape. Those two 'critical' questions don't have the least meaning if we go back to the other dimension of mapping that we have recognized as essential: the navigational one, which, according to our argument, has been refreshed by the recent transmigration of data into digital formats. As James (1996b) would have argued, on the contrary, it is only once we stop asking the mimetic question that there is no longer any doubt as to how connected we are to the real 'outside' world. The 'correspondence theory of truth' - to use a cliché dear to epistemologists - is much more sturdy once many real correspondences have been established between two successive elements along the way. It is much safer to fumble from one signpost to the next than attempt to jump daringly from words to world or from maps to territory (Latour, 2007).

\section{The influence of art history on the interpretation of maps}

Thus, there is nothing obvious, necessary, nor natural in engaging the map in a mimetic adventure. ${ }^{(9)}$ Actually, what is so striking in looking at a two-dimensional map is how little it resembles the world it is supposed to 'reflect'. Hence, the inescapable question: how come, in spite of this huge lack of resemblance, we have been forced to ask the map a mimetic question: do you represent accurately the 'outside' world? The difficult historical question is why the mapping impulse, so clearly engaged in the practice of navigation-in the literal sense, at the time of the Great Discoveries, and later in the more generalized sense made possible by the shift to digital media-has been interpreted mimetically (Cosgrove, 2003; Pickles, 2004). One of the answers might come not from the history of scientific visualization but from art history-especially painting (Casey, 2002).

What is so characteristic of the "art of describing", to use Alpers's (1983) term, is that scientific and artistic visualizations, whatever their many crossovers and overlaps, have one radical difference: scientific inscriptions draw together long series of dissimilar navigational tools, whereas painting defines, by definition, only two endpoints, the prototype and the copy. Each painting, of course, may refer to one another through what literary critics call 'intertextuality', but even if you do not know their author, their topic, their genre, or their value, you may grasp it as something that has meaning in itself: the 'what' that it represents. You do not have to wait, as you do with scientific cascades of inscriptions, for another dissimilar image in order to align both of them into a process of (navigational) correspondence that generates an invisible constant. Painting deals with two endpoints; cartography with many.

So, the argument can be made that it is painting-perspective painting and even more precisely Dutch painting ${ }^{(10)}$ — that has allowed the culture of imagination to shift 
the maps $90^{\circ}$ and to connect them with the one-copy-one-model mode, even though, in terms of practical usage, no one has ever used the maps this way for any navigational purpose. In other words, maps have been aesthetized and fused with the emerging culture of 'realistic' paintings. Quoting Panofsky (1997), we could say: "This too like so many subdisciplines of modern 'science', is in the final analysis the product of the artist's workshop" (page 58).

If this art history argument is correct, we could conclude that the common philosophy of science ('is science a mimetic representation of the "outside" world?'), makes sense for realistic perspective paintings but not so much for science. To put it too crudely, the so called 'realist' philosophy of science is just as realistic as the still-life paintings of the Golden Century (Latour, 2008). As an art history interpretation, it may be fine; as a philosophy of scientific objectivity, it might not be so useful (Ivins, 1973). The realism of scientific inscriptions and especially of maps has always resided elsewhere: in the deambulation from one signpost to the next that it allows.

Our admittedly grand argument is that this second dimension has been rather parasitical on the first and that this parasitic interpretation of maps has created the 'virtual world' of a 'territory' understood not as what is surveyed by the map but rather as a blind alley engaging the map in a destiny for which it was never made and for which it could never succeed (Harley, 1989; Monmonnier, 2005; 2006; 2007).

Fortunately, everything happens as if the AC mapping practices had been freeing the $\mathrm{BC}$ maps of questions that had played, to be sure, a very important role ('is the map like the territory or not?'), but which are immaterial to the real success and import of mapping techniques. Or rather, we understand in retrospect that the very notion of territory is nothing but the 'virtual image' - to use an optical metaphor - of a paper map interrupted in its navigational usage to answer a mimetic interpretation after all its real life users and makers have been all but deleted. This might explain why risk geography is so topical: it is precisely because it cannot rely on a fully calculable universe it has, so to speak, escaped the temptation of producing a spurious referent and is thus well adapted to being mapped in a navigational way. In this case, at least, the long and complex chains of practitioners, signposts, institutions, and warning systems that allow one to find one's way through controversies are what provide risk geography with its objective reality. It is because risk is so controversial that it may be mapped (November, 2002; forthcoming).

\section{Space is a contested territory}

The reason we find probing maps this way so important is that this dissolution of territory as a spurious referent might help improve one of the notions geography has been fighting since its inception: the very notion of space to which the discipline is so attached (Massey, 2005). The question we want now to raise is whether the navigational interpretation of maps may help to revise the idea of space as it is used in geography.

Historians of science, art historians, anthropologists of the industrial societies, and philosophers have always been struck by how unique the notion of space developed in the West since the Renaissance is (Derrida, 1998; Sloterdijk, 2004; Whitehead, 1920). This peculiarly odd notion is best captured by two adjectives: 'Euclidian' and 'Galilean'. In the Western scientific imagination-without, of course, any direct relation with practical realities - the world is made of 'Galilean objects' running through a 'Euclidian space'. The key feature of those Galilean objects is that displacement does not imply any transformation; they are able to move but are themselves immutable, keeping their properties intact as they go (Latour, 1986). As to the Euclidian space, it is the repository inside which Galilean objects move without transformation and are rendered detectable and calculable through their changing positions. 
It does not require a great deal of attention to notice that in both cases the world drawn by Galilean objects moving in Euclidian space furiously resemble a world drawn on paper according to the precise rules of geometry, perspective, and later projective geometry (Ivins, 1973). What Descartes called the res extensa, the material stuff out of which the real world is supposed to be made, has the puzzling characteristic of resembling closely what can be drawn and also calculated on paper. This 'close resemblance' is often (if we dare say) papered over by simply marveling at the sheer coincidence that makes the real world of res extensa so similar to what can be grasped by calculation, thus proving the fabulous power of the human mind - and of God, at least for Descartes.

This 'close resemblance', however, cannot but trigger the nagging suspicion that we might be talking here about a totally different and much less marvelous coincidence: the redoubling of the same world first as drawing and calculation on paper and second as the virtual image of a world represented by those same calculations and on this same paper. The cause for marveling is then rather different than in the first version: why have reasonable people confused the virtual image of the graphic and mathematical invention of three centuries of intellectual technologies with a real world that those technologies would merely 'reflect' as exactly as possible? If you think about it, it is about as odd as to wonder how come there are two strikingly similar images of ourselves when we face a mirror. In effect, we have never been gazing at a world and then at its representation, but rather been engaging with a powerful set of intellectual technologies, so powerful that, when viewed under a certain angle, they project outside a virtual image of the same world with a few odd discrepancies. In other words, there exist representational techniques, and each of them produce a 'what' outside of itself that is being represented. To be sure, the emergence and stability of a virtual image is a fascinating phenomenon (witness Narcissus!), but it is not a phenomenon of correspondence between two different worlds that would mysteriously 'resemble' one another. Hence, the oddity of engaging the mapping impulse, one of the most elaborate intellectual technologies, in mimetic interpretation.

One way to approach this retrospective shift in the understanding of the 'scientific revolution' is to say that 'space' and 'territory' themselves are historical inventionslargely due, as many historians have shown, to the necessity of giving a shape to states (Foucault, 1994). The invention of space could be called a 'res extensa effect', which happens when you look at a map in a certain way and through a certain angle, and when you delete its users and makers - the navigators in all of the $\mathrm{BC}$ and $\mathrm{AC}$ meanings of the word-and erase the six steps of the technology of representation itself to concentrate on the virtual image this technology has projected outward. Then, but only then, you begin to devise a world made by stitching together within your imagination all the virtual images of all the maps (as in figure 2). At this point, a generalized Euclidian space is invented that is the repository of all the territories generated by all the maps. Then you reverse the order, as if we were moving from the abstract 'Euclidian space' to the real 'outside world' and then to the map (as in figure 3). In this view, space is but the virtual image of all the virtual images of all the mapping techniques that have been interpreted in a mimetic way. Paradoxically, res extensa is a by-product of res cogitans - or rather res imaginans. The 'outside material' world might have been engendered by dreaming over overly beautiful maps.

Virtual images, as is well known in optics, appear or disappear depending on the angle at which they are considered. Once the mapping impulse is reinterpreted in the navigational way, there is no longer a projection of a territory, nor of a Euclidian space. All the calculations and signposts are redistributed and embedded inside the world that bears no resemblance with the one that has emerged from mimetic mapping. 


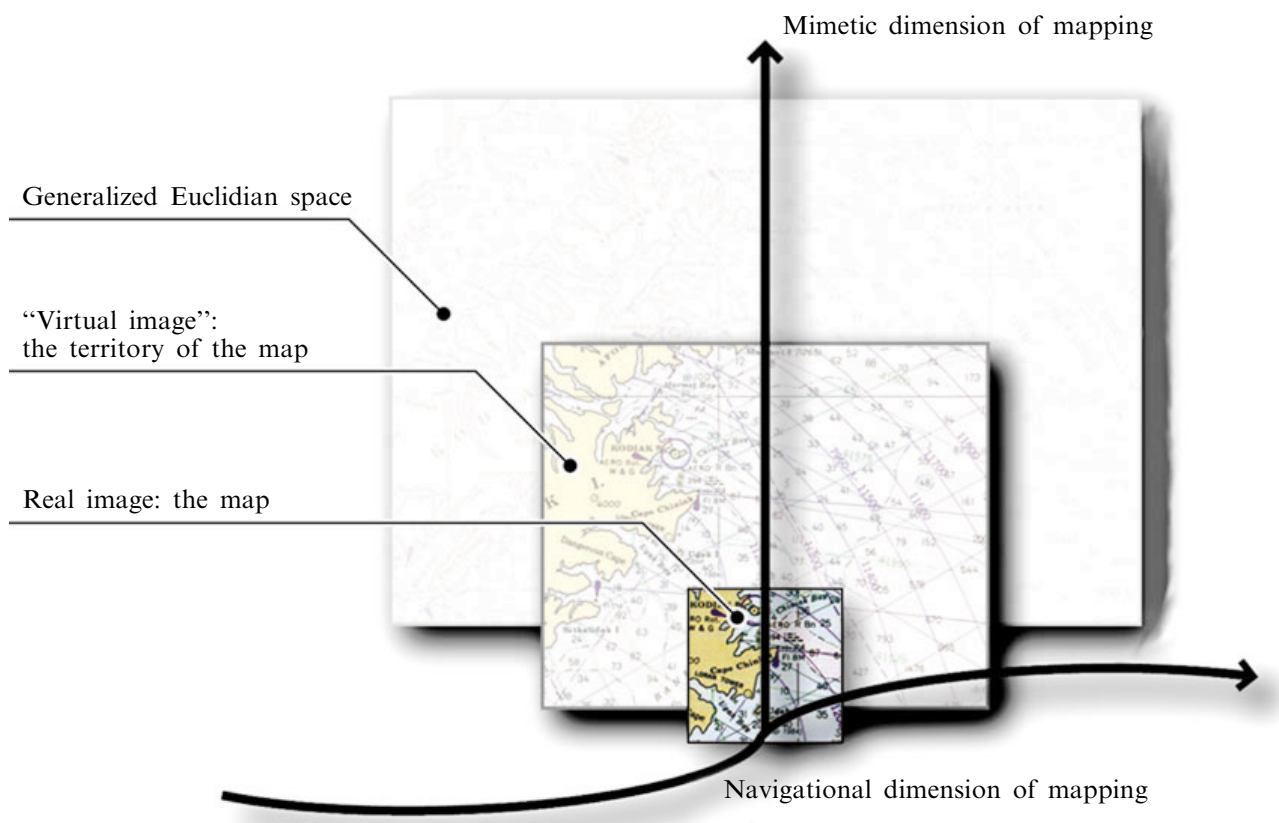

Figure 2 [In color online.] The mimetic interpretation generates a generalized virtual image (source: base map comes from the National Oceanic and Atmospheric Administration; alterations are authors' own).

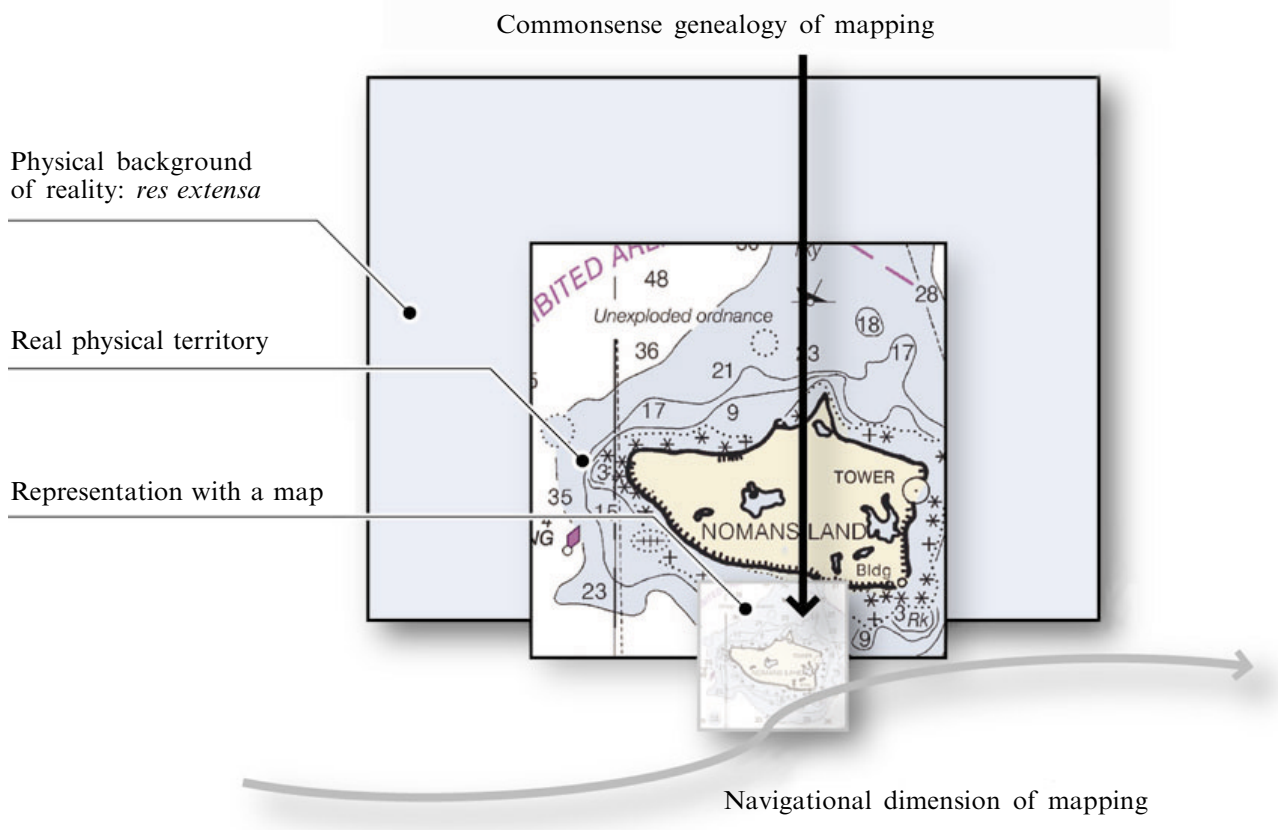

Figure 3 [In color online.] The inversion of the mimetic interpretation makes the map a copy of the model provided. The navigational chain of production has been deleted (source: base map comes from the National Oceanic and Atmospheric Administration; alterations are authors' own). 
If this argument is correct, this would explain why, for so many geographers, 'space' is not a primeval feature of the world (Lévy, 1999; Thrift, 1996; Massey 2005). ${ }^{(11)}$ 'Space' appears and disappears historically as well as visually depending on whether we interpret representational techniques according to mimetic or navigational dimensions. It is our contention that the vastly expanded use of digital mapping renders the historical interpretation that has made space the indispensable category of cartography less commonsense (as if we were collectively moving again from figure 3 to figure 2 and then to figure 1). To navigate on screen is not the same as to imagine that we reside in space. This could throw new light on the efforts of so many scholars to escape the 'tyranny of space' (Law, 2002).

\section{Another take on the difference between 'physical' and 'human' geography}

We may now return to our original puzzle and try to account in a new more productive way for the ease with which 'reefs' enter cartography and the difficulty with which 'risks' were perilously registered inside geography. ${ }^{(12)}$ Where do you put 'risk' on a map?

At first sight, the answer is nowhere (in the mimetic interpretation), since risk is not a feature of the 'outside material' world. But as soon as you shift to a navigational interpretation, 'risk' is just as important to detect on a map as the reefs that threaten the course of your travel - it is not a coincidence that the word risk in insurance and probability emerged in the 16th century among ship owners because it could threaten the maritime enterprise (Beck, 1992; Bernstein 1996). ${ }^{(13)}$ Ask the navigator in the cabin, and she will certainly tell you-and shout to the skipper in the cockpit! - to beware of the risk of hitting some dangerous reef if they do not make sure that the next buoy in line is the one she has been warning them about beforehand and that she has marked in red pencil on her map. The navigator is just as attentive to a dotted line indicating a legal barrier (because of a navy training ground) as she is by an indication of depth or the odd name of a church the spire of which is also used as a landmark. The relations between those heterogeneous sources of data (legal, tidal, toponymical) is what counts for her when she uses the map as a platform for calculation through the database - not especially their 'spatial relations'.

So, as soon as we shift to the navigational interpretation of geographical techniques, we realize that there is nothing especially spatial about geography. Any map is simply one set of inscriptions leading to and coming from another series of dissimilar signposts to help navigators find their way through their trajectories. Or, rather, each entity - the law, the tides, the church-creates several spaces around itself of which only some of their dimensions are entered in the database and queried by the navigator through the interface. In principle, any type of relation may be of interest for building the platform and may be selected on the dashboard provided they allow the navigation to proceed (Camacho-Hübner, 2009; Lévy, 1999; Pointet, 2007).

This argument may free geography from its fascination with the base map, as if any type of data had to be shoehorned onto the topographic grid that has been invented originally, not for any mimetic use but only for navigation (in the literal sense of being on a moving machine-ship, cars, planes, or foot-and trying to anticipate the next

(11) The argument is made even stronger when paralleled by that of time as Glennie and Thrift have shown (2009).

(12) This unease is apparent also within the fragmented study of risks in geography (and, to be fair, not only in this discipline) where natural risks are predominantly being analyzed by physical geography and anthropic risks by human geography.

${ }^{(13)}$ But apparently not because of the spurious etymology that would connect reefs and risks, since the word risk appears to come from an Arabic root meaning the undeserved gift of God. 
signpost with a special emphasis on the conservation of angles). ${ }^{(14)}$ In other words, as so many geographers have argued, the mapping impulse is infinitely more open than cartography, itself much more variegated than topography-digital techniques show that in retrospect. And yet, geography still imagines itself as being locked in topography, on top of which cartography would be overlaid, always with many agonizing scruples about what is allowed to be safely 'shown' on a map. ${ }^{(15)}$

Actually, the very distinction between 'physical' and 'human' geography, a divide that is as old as the bifurcation of nature (Whitehead, 1920) and that cuts across the discipline leading to the split of many academic departments, may be an artifact of engaging the mapping impulse in its mimetic interpretation. And the consequences are obvious on the way risks have traditionally been studied in geography, even though this is rapidly changing thanks to new topics such as climate change (Buckhingham and Turner, 2008; Giddens, 2009; Pelling, forthcoming). It is true that once you have confused the virtual image generated by the mapping techniques with the 'outside material' world it is very difficult to see where you would situate the 'humans' with all their subjective and symbolic enterprises - especially when there is nothing topographical about them. Once, mountains and valleys, capes and rivers have been laid out, and you have transmogrified them into so many Galilean objects moving into a Euclidian space, it is very cumbersome to fit in human industry, economics, risk, travels, and so on, since you pretty well know that they do not 'reside' in Euclidian space and share many more relations than the three sacrosanct ones of height, width, and length.

It is important to realize at this point what our argument is not: it is not another phenomenological attempt to show, once again, that there exists a huge difference between the material world 'as it is known by science' and the 'lived' world as it is practiced by intentional humans. This distinction, no matter how commonsense it seems at first, has plagued geography because it has entrenched the division between 'physical' and 'human' geographies even further, as if the first was a good representation of the 'real world' and the other a necessary complement to account for the 'symbolic' way in which the real world is lived by human subjectivities. What we are arguing instead is that the reduction of the world to Galilean objects flowing effortlessly through Euclidian space is not an especially good representation of the real world either-physical, biological, or human. Thus, there is not the slightest reason to limit the study of 'human' to the symbolic domain either. 'Galilean' and 'Euclidian', after all, are adjectives that relate to highly specific historical sites, Euclid first and then Galileo (Netz, 2003; Biagioli, 1993). Far from being the universal a priori of any metaphysics, they should be inserted into the description of navigational practices with all their local, historical, and anthropological contingencies. Our contention, contrary to that of phenomenology, is that any realistic interpretation of what it is to be 'thrown in' the world, should begin by interrogating anew what the 'scientific world view' is supposed to be (Sloterdijk, 2005). And there is no question that a large part of what we usually mean by 'physical' is an imaginary virtual world born out of intellectual technologies - of which the map is arguably the most impressive.

The point we make, instead, is that mountain, rivers, valleys, capes, and promontories do not sit well in this Euclidian space either. If you do not know where to put the 'humans' on the map, you should be just as concerned about what to do with the nonhumans. No one and no thing ever resided in the virtual image of the map.

(14) Anticipation is, of course, what has been so important in the history of probability (Hacking, 2006).

${ }^{(15)}$ This point is, of course, one of the main concerns in mapping risk issues and making them public and engaging with the Public (in the sense of Dewey) through participative cartography [see Crampton (2009) for recent development in this field]. 
The mountain range on the map bears no more resemblance with the mountain range 'out there' than the village, the economic market, or the recommended roads outlined in green on the tourist's Michelin map. Either you are able to put all of them on the map depending on the precise navigational usages at hand or none of them. Either risks and reefs may cohabit on the map, or you should banish both of them. The real difference is not between 'physical' and 'human' geography but between taking a map mimetically (in which case it does create a difference between human and nonhuman) and taking a map navigationally (in which case there is no relevant difference between the two). What is commonly called the 'outside material' world, the one more or less accurately 'represented' by the maps, is entirely a by-product of the imagination, an aesthetic view of technical practices that have been put in the background. There is nothing especially 'material' in this Euclidian space inside which Galilean objects would flow effortlessly without undergoing any transformation.

To achieve the historical anthropology of the advent of the res extensa would be a major undertaking (and impossible to summarize here anyway), but it is clear to many scholars that the immense shift in imagination that has been called 'the scientific revolution' cannot be understood simply as the progressive or sudden discovery of a Euclidian world over there waiting to be unveiled. What Whitehead (1920) has called the "bifurcation of nature", that is, a division between, on the one hand, "primary qualities' known by science and, on the other, 'secondary qualities', invented by human subjective minds, is not a feature of the world itself but a very specific moment in a history - a moment that had a beginning and fortunately may come to an end, the 'modernist parenthesis' (Latour, 2008). Something entirely different than the discovery of nature has happened for which many disciplines are struggling for words - especially geography.

\section{Conclusion: from space to the multiverse}

What happens when you stop dreaming over maps and you draw again the six steps from section 1? Well, all the virtual images that the mimetic interpretation had been generating begin to fade and vanish, and with them space first and then territories: you resume the course of navigation, and everything is on the move again. As we saw in earlier sections, maps now strike you not as what represent a world 'out there' but as the dashboards of a calculation interface that allows you to pinpoint successive signposts while you move through the world.

But through which world? It is not, of course, the 'outside world' this virtual image produced for your mind only-only Narcissus believes you can reside in this world of fascination. Needless to say that it is also not the 'subjective symbolic' world of human intentional subjects, since this one exists only by contrast with the equally fictitious world of 'primary qualities'. No, the world in which you now try to navigate, thanks to the many scientific techniques that have laid out their long series of inscriptions and instruments, is the real world, but it is not the $3 \mathrm{D}$ world. Since there is no good accepted term - which in itself is odd since it is the only world we all inhabit, humans as well as nonhumans! - we will use James's term, multiverse, indicating by this word that it is indeed just as real as the 'universe' of commonsense but that it has not been prematurely unified through a continuous 'physical space', in effect the res extensa.

What has been so odd with the advent of geography is that not only does it purport to be about 'spatial dimension' but confesses how difficult it is to 'include' the time dimension (see Glennie and Thrift, 2009; Hägerstrand, 1975; May and Thrift, 2001; Schwanen, 2007). But what we just said about the spurious distinction between 'physical' and 'human' geography is even truer of the efforts to add the fourth dimension to the 'three dimensions' of Euclidian space. To be sure, once you believe you have 
frozen the navigational movements in the three dimensions of Euclidian space, it is very difficult to see how you could insert the obvious fact of movement and transformation. But this difficulty vanishes once you realize that in geography - provided you shift to the navigational interpretation of maps-everything is on the move: the navigator in the yacht, the yacht itself, the pencil on the map, the tide, the current, the Nautical Service in charge of sinking the buoys, in brief the whole damned multiverse. The very idea of a time separated from a space (as if a fourth dimension had to be added to the three of 'commonsense' - as if living in a Euclidian space was commonsense!) comes from dreaming over a map too long. Yes, when you engage a map in its mimetic mode, time disappears, but that is because you deal with a frozen image, or synchronic cut (Camacho-Hübner, 2009), selected out of the cascade of transformations inside which it is inserted and because you have deleted all the transformations undergone by the entities you wish to navigate - the yacht, the tide, the reefs, the risks, the race. The very idea of a mobile moving without undergoing any transformation is the result of an aesthetic contemplation of an isolated inscription (Latour, 1986). It is not a property of the world - at least not of the multiverse.

It has been our contention that the massive diffusion of digital technology has allowed not only geographers - they knew that all along - but a much larger public to shift from a mimetic to a navigational interpretation of maps. This shift has the unintended consequence - if pushed to its philosophical origins - of freeing maps from their relationship to a spurious definition of territory. This, in turn, may give a realistic nonsubjective meaning to a whole set of practices that until then had to be divided between an 'objective reality' - often associated with a fond de carte-and 'subjective layers' that had to be added in order to accommodate subjective interpretations. In other words, the mapping impulse might be freed from the 'tyranny of space' (Law, 2002). This might throw a new light on several topics but certainly on risk geography, which has been paralyzed by the distinction between 'subjective' and 'objective' risks, itself a consequence of the entrenchment of the division between 'human' and 'physical' geography. It is now possible to envisage drawing paths through controversial risks without having to abandon objectivity, even though many of the risks are not fully calculable. A whole set of new features, such as anticipation, participation, reflexivity, and feedbacks, might now be included in the navigational definition of maps (November, 2004). We are aware that this new way of looking at risk geography might have interesting political consequences as well (Latour and Weibel, 2002).

Acknowledgements. This paper has been written with the support of the European project MACOSPOL on mapping scientific controversies. We thank Albena Yaneva, Nigel Thrift, Jim Proctor, and the MéThéoGéo collective in Grenoble, as well as two anonymous referees for their useful comments.

\section{References}

Ackerman J (Ed.), 2009 The Imperial Map. Cartography and the Mastery of Empire (University of Chicago Press, Chicago, IL)

Alder K, 2003 The Measure of all Things: The Seven-year Odyssey and Hidden Error that Transformed the World (The Free Press, New York)

Alpers S, 1983 The Art of Describing (University of Chicago Press, Chicago, IL)

Amin A, 2002, "Spatialities of globalisation" Environment and Planning A 34 385-399

Beck U, 1992 Risk Society: Towards a New Modernity (Sage, London)

Beck U, 2002, "The terrorist threat. World risk society revisited" Theory, Culture and Society 19 $39-55$

Bernstein P L, 1996 Against the Gods: The Remarkable Story of Risk (Wiley, New York)

Biagioli M, 1993 Galileo Courtier: The Practice of Science in the Culture of Absolutism (Chicago University Press, Chicago, IL)

Bingham N, Thrift N, 2000, "Some new instructions for travellers : the geography of Bruno Latour and Michel Serres", in Thinking Space Eds M Crang, N Thrift (Routledge, London) pp 281 - 301 
Borges J L, 2004 [1946] A Universal History of Iniquity (Penguin, London)

Bowker G C, 2006 Memory Practices in the Sciences (MIT Press, Cambridge, MA)

Buckhingham S, Turner M, 2008 Understanding Environmental Issues (Sage, London)

Callon M, Law, J, 2004, "Introduction: absence-presence, circulation, and encountering in complex space" Environment and Planning D: Society and Space 22 3-11

Camacho-Hübner E, 2009 Traduction des Opérations de l'Analyse Historique dans le Langage Conceptuel des Systèmes d'Information Géographique pour une Exploration des Processus Morphologiques de la Ville et du Territoire PhD dissertation EPFL-ENAC, Lausanne

Carpo M, 2001 Architecture in the Age of Printing: Orality, Writing, Typography, and Printed Images in the History of Architectural Theory translated by S Benson (Cambridge University Press, Cambridge)

Cartwright W, 1999, "Extending the map metaphor using web delivered multimedia" International Journal of Geographical Information Science 13(4) 335-353

Cartwright W, Hunter G, 1999, "Enhancing geographical information resources with multimedia", in Multimedia Cartography Eds W Cartwright, M P Peterson, G Gartner (Springer, Berlin) pp $257-270$

Casey E, 2002 Representing Place: Landscape, Painting and Maps (University of Minnesota Press, Minneapolis, MN)

Chrisman N, 1997 Exploring Geographic Information Systems (Wiley, New York)

Collectif, 1980 Cartes et Figures de la Terre. Catalogue de l'Exposition du Centre Georges Pompidou (Centre Georges Pompidou, Paris)

Cosgrove D (Ed.), 1999 Mappings (Reaktion Books, London)

Cosgrove D, 2003, "Historical perspectives in an age of digital media", in Mapping in an Age of Digital Media Eds M Silver, D Balmori (Wiley-Academy, New York) pp 128 - 137

Crampton J W, 2003 The Political Mapping of Cyberspace (Edinburgh University Press, Edinburgh)

Crampton J W, 2009, "Cartography: performative, participatory, political" Progress in Human Geography $33840-848$

Crary J, 1990 Techniques of the Observer. On Vision and Modernity in the Nineteenth Century (MIT Press, Cambridge, MA)

Daston L, Galison P, 2007 Objectivity (University of Chicago Press, Chicago, IL)

Debarbieux B, 1999, "Le territoire: histoire en deux langues. A bilingual (his-)story of territory", in Discours Scientifiques et Contextes Culturels: Géographies Françaises à l'Épreuve Postmoderne Eds C Chivaillon, P Ragouet, M Samers (MSHA, Bordeaux) pp 33-46

Derrida J, 1998 Of Grammatology translated by G Chakravorty Spivak (Johns Hopkins University Press, Baltimore, MD)

Dodge M, Kitchin R, 2005, "Code and the transduction of space" Annals of Association of American Geographers $95162-180$

Dodge M, Kitchin R, Perkins C, 2009 Rethinking Maps (Routledge, London)

Elden S, 2005, "Missing the point: globalization, deterritorialization and the space of the world" Transactions of the Institute of British Geographers, New Series $308-19$

Fabrikant S I, 2000 Spatial Metaphors for Browsing Large Data Archives (University Press of Colorado, Boulder, $\mathrm{CO}$ )

Fabrikant S I, Buttenfield B P, 2001, "Formalizing semantic spaces for information access" Annals of the Association of American Geographers 91263 - 280

Fall J J, 2007, "Lost geographers: power games and the circulation of ideas within Francophone political geographies" Progress in Human Geography 31 195-216

Foucault M, 1994 The Order of Things: An Archaeology of the Human Sciences (Vintage Books, New York)

Giddens A, 2009 The Politics of Climate Change (Polity Press, Cambridge)

Glennie P, Thrift N, 2009 Shaping the Day: A History of Timekeeping in England and Wales $1300-1800$ (Cambridge University Press, Cambridge)

Goodchild M, 2007, "Citizens as sensors: the world of volunteered geography" GeoJournal 69 $211-221$

Hacking I, 2006 The Emergence of Probability: A Philosophical Study of Early Ideas about Probability: Induction and Statistical Inference 2nd edition (Cambridge University Press, Cambridge)

Hägerstrand T, 1975, "Space, time and human conditions", in Dynamic Allocation of Urban Space Eds A Karlsqvist, L Lundqvist, F Snickars (Saxon House, Farnborough, Hants) pp 3-14

Harley B, 1989, "Deconstructing the map" Cartographica 26 1-20 
Harrisson S, Massey D, Keith R, Magilligan F, Thrift N, Bender B, 2004, "Thinking across the divide: perspectives on the conversations between physical and human geography" Area $\mathbf{3 6}$ $435-442$

Healy S, 2004, "A 'post-foundational' interpretation of risk: risk as 'performance" "Journal of Risk Research $7277-296$

Hetherington K, 1997, "In place of geometry: the materiality of place", in Ideas of Difference: Social Spaces and the Labour of Division Eds K Hetherington, R Munro (Blackwell, Oxford) pp $183-199$

Hetherington K, Law J, 2000, "After networks" Environment and Planning D: Society and Space $18127-132$

Hinchliffe S, 1996, "Technology, power, and space - the means and ends of geographies of technology" Environment and Planning D: Society and Space 14 659-682

Hutchins E, 1995 Cognition in the Wild (MIT Press, Cambridge, MA)

Ingold T, 2007 Lines: A Brief History (Routledge, London)

Ivins W M, 1973 [1930] On the Rationalization of Sight: With an Examination of Three Renaissance Texts on Perspective (De artificiali perspectiva) reproducing both the 1st edition (Toul, 1505) and the 2nd edition (Toul, 1509) (De Capo Press/Plenum Press, New York)

Jacob C, 1992 L'Empire des Cartes; Approche Théorique de la Cartographie à Travers l'Histoire (Albin Michel, Paris)

James W, 1996a [1907] Essays in Radical Empiricism (University of Nebraska Press, London)

James W, 1996b [1909] A Pluralistic Universe (University of Nebraska Press, London)

Jones M, 2009, "Phase space: geography, relational thinking, and beyond" Progress in Human Geography $33487-506$

Kitchin R, Dodge M, 2007, "Rethinking maps" Progress in Human Geography 31331 - 344

Lane S, 2001, "Constructive comments on D Massey 'Space - time, "science" and the relationship between physical and human geography", Transactions of the Institute of British Geographers, New Series $26243-256$

Latour B, 1986, "Visualisation and cognition: thinking with eyes and hands" Knowledge and Society. Studies in the Sociology of Culture Past and Present $61-40$

Latour B, 1987 Science in Action: How to Follow Scientists and Engineers through Society (Harvard University Press, Cambridge, MA)

Latour B, 1993 We Have Never Been Modern translated by C Porter (Harvard University Press, Cambridge, MA)

Latour B, 1997, "Trains of thought: Piaget, formalism, and the fifth dimension" Common Knowledge $3170-191$

Latour B, 1999 Pandora's Hope: Essays on the Reality of Science Studies (Harvard University Press, Cambridge, MA)

Latour B, 2005 Reassembling the Social (Oxford University Press, Oxford)

Latour B, 2007, "A textbook case revisited: knowledge as mode of existence" in The Handbook of Science and Technology Studies 3rd edition, Eds E Hackett, O Amsterdamska, M Lynch, J Wacjman, (MIT Press, Cambridge) pp $83-112$

Latour B, 2008 What is the Style of Matters of Concern: Two Lectures on Empirical Philosophy (Van Gorcum, Amsterdam)

Latour B, Weibel P (Eds), 2002 Iconoclash: Beyond the Image Wars in Science, Religion and Art (MIT Press, Cambridge, MA)

Law J, 2002, "Objects and spaces" Theory, Culture and Society 19(5/6) 91 - 105

Law J, 2004, "And if the global were small and noncoherent? Method, complexity, and the baroque" Environment and Planning D: Society and Space $2213-26$

Law J, Mol A, 2001, "Situating technoscience: an inquiry into spatialities" Environment and Planning D: Society and Space $19609-621$

Lévy J, 1994 L'Espace Légitime: Sur la Dimension Géographique de la Fonction Politique (Presses de la Fondation Nationale des Sciences Politiques, Paris)

Lévy J, 1999 Le Tournant Géographique: Penser l'Espace pour Lire le Monde (Belin, Paris)

Lévy J, Lussault M (Eds), 2003 Dictionnaire de la Géographie et de l'Espace des Sociétés (Belin, Paris)

Lussault M, 2007 L'Homme Spatial: La Construction Sociale de l'Espace Humain (Seuil, Paris)

Lynch M, Woolgar S (Eds), 1990 Representation in Scientific Practice (MIT Press, Cambridge, MA)

Massey D, 2000, "Space-time, 'science' and the relationship between physical and human geography" Transactions of the Institute of British Geographers, New Series 24261 - 276

Massey D, 2005 For Space (Sage, London)

May J, Thrift N (Eds), 2001 TimeSpace: Geographies of Temporality (Routledge, London) 
Monmonier M, 1997 Cartographies of Danger: Mapping Hazards in America (University of Chicago Press, Chicago, IL)

Monmonier M, 2005, "Cartography: distortions, world-views and creative solutions" Progress in Human Geography 29217 - 224

Monmonier M, 2006, "Cartography: uncertainty, interventions, and dynamic display" Progress in Human Geography 30373 - 381

Monmonier M, 2007, "Cartography: the multidisciplinary pluralism of cartographic art, geospatial technology, and empirical scholarship" Progress in Human Geography 31371 - 379

Murdoch J, 1997, "Towards a geography of heterogeneous associations" Progress in Human Geography $21321-337$

Murdoch J, 1998, "The spaces of actor-network theory" Geoforum 29357 - 374

Netz R, 2003 The Shaping of Deduction in Greek Mathematics: A Study in Cognitive History (Cambridge University Press, Cambridge)

November V, 2002 Les Territoires du Risque: Le Risque comme Objet Géographique (Peter Lang, Bern)

November V, 2004, "Being close to risk: from proximity to connexity" International Journal of Sustainable Development 7273 - 286

November V, 2008, "Spatiality of risk" Environment and Planning A 401523 - 1527

November V, forthcoming, "Recalcitrance of risks: a management failure?" Science Studies in press

Paasi A, 2003, "Territory", in A Companion to Political Geography Eds J Agnew, K Mitchell, G Ó Tuathail (Blackwell, Oxford) pp 109-122

Painter J, 2009, “Territoire et réseau: une fausse dichotomie?" [Territory and network: a false dichotomy?], in Territoires, Territorialité, Territorialisation: Controverses et Perspectives Ed. M Vanier (Presses Universitaires, Rennes) pp 57-66

Panofsky E, 1997 Perspective as Symbolic Form (Zone Books, New York)

Pelling M, forthcoming Adaptation to Climate Change: A Progressive Vision of Human Security (Routledge, London)

Pickles J, 2004 A History of Spaces: Cartographic Reason, Mapping and the Geo-coded World (Routledge, London)

Pinch T, 1986 Confronting Nature: The Sociology of Neutrino Detection (Reidel, Dordrecht)

Pointet A, 2007 Rencontre de la Science de l'Information Géographique et de l'Anthropologie Culturelle: Modélisation Spatiale et Représentation des Phénomènes Culturels $\mathrm{PhD}$ dissertation, EPFL-ENAC, Lausanne

Raffestin C, 1986, "Écogenèse territoriale et territorialité", in Espaces, Jeux et Enjeux Eds F Auriac, R Brunet (Fayard, Paris) pp $173-185$

Raffestin C, 1997, "Le rôle des sciences et des techniques dans les processus de territorialisation" Revue Européenne des Sciences Sociales 10893 - 106

Schwanen T, 2007, "Matter(s) of interest: artefacts, spacing and timing" Geografiska Annaler, Series B 89(1) 9-22

Sheppard E, 2002, "The spaces and times of globalization: place, scale, networks, and positionality" Economic Geography $78307-330$

Sloterdijk P, 2004 Sphären III: Schäume (Suhrkamp, Frankfurt am Main)

Sloterdijk P, 2005, "Foreword to the theory of spheres", in Cosmograms Eds M Ohanian, J C Royoux (Lukas and Sternberg, New York) pp 223-241

Thrift N, 1996 Spatial Formations Theory, Culture and Society Series (Sage, London)

Thrift N, 2002, "The future of geography" Geoforum 33291 - 298

Thrift N, 2004, "Movement - space: the changing domain of thinking resulting from the development of new kinds of spatial awareness" Economy and Society $33582-604$

Trystram F, 2001 Le Procès des Étoiles: Récit de la Prestigieuse Expédition de Trois Savants Français en Amérique du Sud, 1735 - 1771 (Payot, Paris)

Vertesi J, 2008, "Mind the gap: the London underground map and users' representations of urban space" Social Studies of Science 38 7-33

Whatmore S, 2002 Hybrid Geographies (Sage, London)

Whitehead A N, 1920 Concept of Nature (Cambridge University Press, Cambridge) 
Conditions of use. This article may be downloaded from the E\&P website for personal research by members of subscribing organisations. This PDF may not be placed on any website (or other online distribution system) without permission of the publisher. 